\title{
Solo sé que no sé nada
}

\author{
Eugenio Martín Diéguez \\ Director General Arquetipo
}

\section{Referencia de este artículo}

Martín Diéguez, Eugenio (2019). Solo sé que no sé nada. adComunica. Revista Científica de Estrategias, Tendencias e Innovación en Comunicación, (18). 297-300. DOI: http://dx.doi.org/10.6035/2174-0992.2019.18.14

Quizá la frase más comentada de la historia y quizá el mejor slogan del conocimiento, atribuido a Sócrates, sea un buen comienzo para reflexionar sobre nuestra profesión y sobre la industria publicitaria en general, en este primer cuarto del siglo XXI.

La primera reflexión, y no es nueva, es que esta profesión está cambiando. Ahora está de moda hablar de que lo único que no cambia es el cambio, pero los publicitarios hemos estado cambiando desde que nació esta forma de ayudar a vender y de ayudar a conseguir marcas con seguidores y buena reputación. Y no hace tanto tiempo de esto. Es bueno pensar que somos una profesión muy joven, como mucho setenta años, frente a otras que llevan cientos de años y eso, hace que estemos constantemente atentos a los cambios.

Con la irrupción de Internet, todo se ha visto acelerado de forma radical y estresante, creando una verdadera convulsión en nuestra profesión, un aspecto a destacar dentro del panorama de las agencias, donde todos los actores quieren estar presentes y no todos de forma exitosa.

En este sentido, también estamos con las modas, un sinfín de posibilidades en un universo líquido que parece mucho pero que, a veces, se queda diluido en nada. Youtubers, Instagramers, influencers, un baile al que entran las marcas y no pocas 
veces salen trasquiladas, sobre todo cuando se atreven solas sin la ayuda de una pensada estratégica y profesional que centre bien los tiros.

Esa es nuestra posición: aportar cordura y profesionalidad, conduciendo discursos corporativos coherentes, sea para el mundo off o para el on.

Pero, para ello, no debemos perder nuestro rol: Pensar en los objetivos de las empresas, saber qué recursos tenemos, plantear estrategias definidas, seguir apostando por la creatividad y el arte del buen hacer y explorar todas las posibilidades que tenemos sin atiborrarse de paja.

Parece sencillo, pero es complejo. Las agencias estamos acostumbradas a los diversos campos de batalla donde conducir las tropas por terrenos hostiles y llegar a resultados con esfuerzo, imaginación y, muchas veces, pocos apoyos logísticos, pero no sabemos vender bien ese valor añadido que aportamos $\mathrm{y}$, desde fuera, parece fácil y salta la tentación de prescindir de nuestro trabajo. Es el gran error del universo empresarial, con las excepciones que nos mantienen en el ajo, porque saben todas las dificultades de nuestro trabajo multidisciplinar.

A esto también estamos acostumbrados, es más, puedo asegurar que una de nuestras disciplinas está en la parte pedagógica de enseñar a los clientes las virtudes de confiar en las agencias profesionales.

¿Tradicional o Digital? Qué más da, si ya no podemos obviar ninguno de los universos que se interpenetran. Si hay un cliente que necesita especialización, las agencias buscamos cómo establecer los mejores mecanismos para conseguir los objetivos adecuados. Por la cuenta que nos trae.

Si fuimos los pioneros en la comunicación no publicitaria, puesto que las grandes compañías publicitarias fueron las que visualizaron que había que comunicar con la credibilidad de los medios más allá de los anuncios comerciales, y se montaron las empresas de RR.PP. y Comunicación Estratégica, cómo no vamos a poder transitar los nuevos escenarios. Somos especialistas en los cambios, en adaptarnos, en tragar amargo y escupir dulces campañas y trabajos que han ayudado de forma excepcional a muchas empresas, a muchas marcas, a muchos productos.

Pasamos de la publicidad en pañales a la publicidad psicológica, para más tarde meternos en la sociológica y antropológica. Ahora estamos descubriendo las posibilidades de un nuevo mundo digital e infinito, compuesto por una sociedad líquida como ha descrito magistralmente Zygmunt Bauman y esto nos hace perder las referencias. Pero las encontraremos, ¿alguien lo duda?

Soy optimista porque esta profesión, que amo, me ha dado muchas alegrías y la posibilidad de hacer proyectos increíbles con resultados fantásticos. Siempre habrá clientes que apuesten por nuestros criterios y nos dejarán trabajar, pero no olvidemos que debemos aportar profesionalidad, visión y creatividad con coherencia.

Las nuevas generaciones están que se salen y pueden aportar mucho a la profesión, pero deben colocarse ante un rol fundamental: Tienen que ser profesionales de la 
comunicación por encima de las modas o las poses. Los que realmente construyeron esta profesión no lo hicieron con postureo, sino trabajando duro y ganándose todos los días la confianza de los clientes y la sociedad.

Propongo una mezcla generacional de experiencia y dinamismo y conocimiento de los nuevos escenarios para conseguir la mezcla explosiva que nos relance hacia una influencia perdida. Estoy seguro que lo conseguiremos, simplemente porque somos fabricantes de contenidos y sueños, ¿hay alguien que de más? 
